\title{
THE QUALITY OF CARE PROVIDED TO PATIENTS WITH CHRONIC NON-COMMUNICABLE DISEASES: RETROSPECTIVE MULTI-SETUP STUDY IN JIMMA ZONE, SOUTHWEST ETHIOPIA.
}

\author{
Yibeltal Kiflie* $^{\mathbf{1}}$, Challi Jira ${ }^{1}$, Dereje Nigussie ${ }^{2}$
}

\begin{abstract}
BACKGROUND: Chronic Non-Communicable Diseases are among the major causes of morbidity and mortality worldwide. However, access to and quality of health care for patients is very low in developing countries including Ethiopia. Hospitals and Health Centers are the main sources of health care for such patients in Ethiopia. In this study we assessed the quality of care patients with Chronic NonCommunicable Diseases received in hospital and health center setups.

METHODS: A retrospective multi-setup study was conducted in Jimma University Specialized Hospital and four Health Centers in Jimma Zone from February to March 2010. A total of 52 process indicators of quality covering three disease conditions: Diabetes, Hypertension and Epilepsy were measured by reviewing randomly selected medical records. Quality of care was measured as a proportion of recommended components of care actually provided to patients. And also outcome and structural measures were assessed to supplement process measures of quality.

RESULTS: Six hundred seventy four medical records were reviewed. Recommended care components were actually provided to patients in $35.1 \%$ (95\%CI:34.1\%,36.0\%), 38.5\% (95\%CI:37.5\%,39.5\%) and 60.1\% (95\% CI:59.3\%,61.0\%) of times on which patients were eligible, among patients with Diabetes, Hypertension and Epilepsy, respectively. After case mix adjustment, it was found that 45.9\% (95\% CI:45.4\%,46.5\%) of recommended components of care was actually provided to patients. This was 45.1\% (95\%CI:44.4\%,45.8\%) in the hospital and 30.5\% (95\%CI:29.7\%,31.3\%) in the health centers. Among patients for whom outcome data was available, optimal level of disease control was achieved only for 47 (30.5\%), 40(38.5\%) and 193 (52.9\%) of patients with Diabetes, Hypertension and Epilepsy, respectively.
\end{abstract}

CONCLUSION: The quality of care provided to patients with Chronic Non-Communicable Diseases is very low in both settings though it is relatively better in Jimma University Specialized Hospital. Therefore, a continuous process of quality improvement is recommended in both settings.

KEYWORDS: Health care, Health care quality, Quality indicators, Guideline Adherence, Chronic diseases, Diabetes, Hypertension, Epilepsy

\footnotetext{
${ }^{1}$ Department of Health Services Management, College of Public Health and Medical Sciences, Jimma University, Jimma, Ethiopia

${ }^{2}$ Department of Obstetrics and Gynecology, College of Public Health and Medical Sciences, Jimma University, Jimma, Ethiopia

"Corresponding Author: E-mail- yibeltal.kiflie@ju.edu.et
} 


\section{INTRODUCTION}

According to reports from the World Health Organization, chronic non-communicable diseases (CNCDs) are among the major causes of morbidity and mortality contributing for more than half of all deaths all over the world (1). In contrary to the traditional view to CNCDs as diseases of the affluent, high prevalence and incidence rates of cardiovascular diseases and Diabetes mellitus are reported by studies in different developing countries (2-6). However, access to and quality of health care for patients is very low in developing countries leading to compromised quality of life and premature deaths (7-9). According to a systematic review of published population based studies on Hypertension in Sub-Saharan Africa, less than $40 \%$ of people with blood pressure (BP) above the normal range are diagnosed as hypertensive; less than $30 \%$ of diagnosed cases are on treatment, and only less than $20 \%$ of them had BP within the defined normal range (3).

As in any other developing countries, Ethiopia is challenged by the growing magnitude of CNCDs which created a double burden on the population and the health system which is already hard hit by communicable diseases. Available population based studies indicated high prevalence of CNCDs including hypertension, other cardiovascular diseases, diabetes and epilepsy, in both rural and urban parts of the country (10-16).

On the other hand, the Ethiopian health system is designed primarily for the prevention and control of communicable diseases, giving very little emphasis on CNCDs (17). Patients with CNCDs have limited access to health care and even those under treatment are very likely to have uncontrolled disease conditions leading to high rate of complications and premature deaths (1013,18-20). A study conducted among patients with Rheumatic Heart Disease attending chronic care clinic in JUSH identified perception of beneficiaries about illness, quality of care and the balance between cost and benefits of health care as important determinants of seeking medical care (21).

With the aim of improving access to services, some initiatives have been started integrating management of patients with CNCDs with primary health care through decentralization of care from hospitals to health centers $(20,22,23)$. However, there is paucity of information regarding the quality of care provided in both settings. There are no studies conducted to assess the implication of such efforts on the quality of clinical care patients receive for CNCDs. Understanding the quality of clinical care provided in these settings will help decision makers in the health sector to identify priority areas for quality improvement that need to be addressed in line with efforts for the expansion of the services. This study was therefore, conducted to assess the quality of health care provided to patients with CNCDs in hospital and health center setups and explores the need for quality improvement in the area. The findings of the study could also serve as feedback for the already started process of decentralizing chronic care from hospitals to health center levels.

\section{METHODS AND MATERIALS}

A retrospective multi-setup study was conducted to assess the quality of clinical care provided to patients with CNCDs in hospital and health center settings, in Jimma Zone, South west Ethiopia. The study was conducted from February to March 2010 and the review covered clinical care provided to patients in the health facilities from February 2009 to January 2010.

After a thorough review of the scientific literature on health care quality specifically for Diabetes, Hypertension and Epilepsy, we selected a total of 52 process indicators of quality, 17 for Diabetes, 22 for Hypertension and 13 for Epilepsy. Criteria for eligibility were developed for each indicator and the selected indicators were reviewed by a local internal medicine specialist for their local relevance. Medical record reviewing tools were developed and pre-tested for the three disease conditions. The tools included variables on eligibility of patients for selected quality of care indicators and whether these indicators were met for eligible patients. In addition, general background information of patients and indicators of disease control were included to supplement the process indicators of quality. A resource inventory tool was used to collect health facility level data 
on required resources for the management of CNCDs.

Jimma University Specialized Hospital is a hospital with the highest load of patients with CNCDs in Jimma Zone. And Jimma Health Center, Agaro Town Health Center, Shebe Health Center and Asendabo Health Center, supported by JUSH, were the major Health Center level clinical care providers for such patients in the zone. Jimma University Specialized Hospital and the four health centers were selected as study health facilities for they had high patient load from their respective settings.

A representative sample of patients attending chronic illness clinics for Diabetes mellitus, Hypertension and Epilepsy in JUSH and the four study Health Centers constituted the study population for this study. Sample size was determined using sample size calculation formula for comparison of proportions, $\mathrm{n}=\left[\pi_{1}\left(1-\pi_{1}\right)+\pi_{2}\right.$ $\left(1-\pi_{2}\right)$ ] X F / D ${ }^{2}$ where $\pi_{1}$ and $\pi_{2}$ represent the proportion of recommended components of care actually provided to patients in the two study setups. $\pi_{1}$ was considered as 0.5 to get the safest sample size in the absence of previously published local studies on the subject. D, representing the minimum difference to be identified was decided to be $10 \%(0.1)$ and $\pi_{2}$ was calculated as $\pi_{1}-\mathrm{D}$. For $95 \%$ confidence level and $80 \%$ power, the value of $\mathrm{F}$ was 7.9. The resulting sample size, 387, was considered as the sample size for both settings making a total sample size of 774 . The calculated sample size for both settings was distributed among patients with the three disease conditions proportionally based on the number of patients attending follow-up care. And allocation of sample size among the four health centers was made based on their patient load. Systematic sampling technique was used to select medical records of patients from the stack of patient charts for patients with CNCDs. Patients enrolled to chronic care in the study health facilities at least six months prior to the data collection period and had at least one clinic visit during the one year review period were considered eligible for the study.

A team of four medical interns and one resident physician collected the data after receiving training on data collection procedures and tools. Permission to conduct the study was obtained from involved health facilities through a letter of collaboration written from Jimma University. Data was collected by reviewing medical records of sample patients attending follow-up care for CNCDs in the study health facilities and personal identifier was recorded neither for patients nor for health care providers.

Overall quality of care was analyzed for the three categories of patients, as proportion of recommended care components found received by patients. The measure was calculated using overall percentage and patient average calculation techniques, discussed by Reeves D et al (24). The total number of indicators for which eligibility criteria were met was considered as denominator and the total number of times these indicators were found met was considered as the numerator. This measure was applied at individual patient level for patient average technique and for the whole study population for overall percentage technique. We used SPSS for Windows Version 16.0 for data entry and analysis. Both descriptive and analytical statistics were applied. Ms-Excel was used to calculate summary values by aggregating findings on multiple indicators. To compare overall quality of care for patients with CNCDs between JUSH and Health Centers, case mix adjustment was made prior to aggregating data on the three disease conditions.

Operational Definitions: In this study we defined "Lost to follow-up" as missing a clinic appointment for more than a month. Optimal level of disease control was defined for patients with Diabetes Mellitus as having a Recent Fasting Blood Sugar (FBS) level of less than $126 \mathrm{mg} / \mathrm{dL}$; for patients with Hypertension as average Systolic BP of less than $140 \mathrm{mmHg}$ and average Diastolic BP of less than $90 \mathrm{mmHg}$ based on three most recent BP measures; and for patients with Epilepsy: a minimum of one seizure free year prior to the data collection time. 


\section{RESULTS}

Medical records of 363 patients from JUSH and 311 patients from the four health centers were reviewed yielding coverage of $93.8 \%$ and $80.4 \%$, respectively. Four hundred $(59.3 \%)$ of the patients were male and the majority $(80.3 \%)$ were aged 18 years or older. Six hundred twenty eight (93.2\%) of the study subjects were from within Jimma Zone (Table 1). Study patients attended follow-up care in the study health facilities for a median period of 44.7 months, Inter-Quartile Range (IQR) (22.7 months, 76.0 months).

Table 1: Characteristics of study patient, Health Facilities in Jimma Zone, 2010, $n=674$

\begin{tabular}{llrrr}
\hline Variable & Categories & $\begin{array}{r}\text { Hospital } \\
\mathbf{n}(\boldsymbol{\%})\end{array}$ & $\begin{array}{r}\text { Health Centers } \\
\mathbf{n}(\boldsymbol{\%})\end{array}$ & $\begin{array}{r}\text { Total } \\
\mathbf{n}(\boldsymbol{\%})\end{array}$ \\
\hline Disease & Diabetes Mellitus & $114(31.4)$ & $60(19.3)$ & $174(25.8)$ \\
& Hypertension & $125(34.4)$ & $10(3.2)$ & $135(20.0)$ \\
Age Group & Epilepsy & $124(34.2)$ & $241(77.5)$ & $365(54.2)$ \\
& $<18$ years & $53(14.6)$ & $68(21.9)$ & $121(18.0)$ \\
& $\geq 18$ years & $305(84.0)$ & $236(75.9)$ & $541(80.3)$ \\
Sex & Not documented & $5(1.4)$ & $7(2.3)$ & $12(1.8)$ \\
& Male & $212(58.4)$ & $188(60.5)$ & $400(59.3)$ \\
& Female & $137(37.7)$ & $116(37.3)$ & $253(37.5)$ \\
Address (Zone) & Not documented & $14(3.9)$ & $7(2.3)$ & $21(3.1)$ \\
& Jimma & $337(92.8)$ & $291(93.6)$ & $628(93.2)$ \\
& Outside Jimma & $24(6.6)$ & $3(1.0)$ & $27(4.0)$ \\
& Not documented & $2(0.6)$ & $17(5.5)$ & $19(2.8)$ \\
\hline
\end{tabular}

\section{General level of adherence to recommended processes of care}

Level of adherence to recommended components of care was assessed against 52 selected process indicators of quality covering Diabetes, Hypertension and Epilepsy. Eligibility criteria for these indicators were met in 2595, 2505 and 3292 number of times for patients with Diabetes, Hypertension and Epilepsy, respectively. Of these, recommended processes of care were met only in $910(35.1 \%), 964(38.5 \%)$ and $1979(60.1 \%)$ of the encounters for patients with Diabetes, Hypertension and Epilepsy, respectively (Table 2).

Patients attending chronic illness follow-up in JUSH were found to receive significantly higher proportion of recommended processes of care as compared to those at the health centers. A recommended process of care was found 2.0, 2.6 and 1.2 times more likely to be provided for a patient at JUSH as compared to those in health centers for Diabetes, Hypertension and Epilepsy, respectively. 
Table 2: Overall level of adherence to recommended processes of care by health facility and disease type, analyzed using overall percentage technique, Health Facilities in Jimma Zone, 2010.

\begin{tabular}{|c|c|c|c|c|c|}
\hline $\begin{array}{l}\text { Disease } \\
\text { (No of } \\
\text { indicators) }\end{array}$ & $\begin{array}{l}\text { Type of } \\
\text { health facility }\end{array}$ & $\begin{array}{r}\begin{array}{r}\text { Number } \\
\text { of } \\
\text { patients }\end{array}\end{array}$ & $\begin{array}{r}\text { Number of times } \\
\text { patients found } \\
\text { eligible for quality } \\
\text { indicators }\end{array}$ & $\begin{array}{l}\text { Number of } \\
\text { times indicators } \\
\text { met for patients }\end{array}$ & $\begin{array}{r}\% \text { of indicators } \\
\text { met, Mean } \\
(95 \% \mathrm{CI})\end{array}$ \\
\hline Diabetes & Hospital & 114 & 1717 & 688 & $40.1(38.9,41.3)$ \\
\hline Mellitus & Health Centers & 60 & 878 & 222 & $25.3(23.8,26.8)$ \\
\hline (17 indicators) & Both settings & 174 & 2595 & 910 & $35.1(34.1,36.0)$ \\
\hline \multirow{3}{*}{$\begin{array}{l}\text { Hypertension } \\
\text { (22 indicators) }\end{array}$} & Hospital & 125 & 2319 & 926 & $39.9(38.9,40.9)$ \\
\hline & Health Centers & 10 & 186 & 38 & $20.4(17.5,23.4)$ \\
\hline & Both settings & 135 & 2505 & 964 & $38.5(37.5,39.5)$ \\
\hline \multirow{3}{*}{$\begin{array}{l}\text { Epilepsy } \\
\text { (13 indicators) }\end{array}$} & Hospital & 124 & 1158 & 730 & $63.0(61.6,64.5)$ \\
\hline & Health Centers & 241 & 2134 & 1249 & $58.5(57.5,59.6)$ \\
\hline & Both settings & 365 & 3292 & 1979 & $60.1(59.3,61.0)$ \\
\hline
\end{tabular}

Aggregation of the data on multiple indicators through a different approach, patient averaging technique (24), was made to see if the findings change based on the analytic approach used. A significant difference still exists in the quality of care provided to patients in the two setups. Average value for proportion of indicators that were met at individual level was significantly higher for patients attending care in the hospital as compared to those in the health centers, with a difference of $14.9 \%, 95 \%$ CI $(11.8 \%, 18.0 \%)$ for Diabetes, $19.7 \%$, 95\%CI $(14.7 \%, 24.7 \%)$ for Hypertension and $4.8 \%, 95 \%$ CI $(1.5 \%, 8.1 \%)$ for Epilepsy (Table 3).

Table 3: Average percentage of adherence to recommended processes of care by hospital and disease type, analyzed using patient average technique, Health Facilities in Jimma Zone, 2010

\begin{tabular}{lrcrr}
\hline & \multicolumn{4}{c}{ *Average percentage of criteria met } \\
\cline { 2 - 5 } Disease & $\begin{array}{r}\text { Hospital } \\
\text { (JUSH) }\end{array}$ & $\begin{array}{c}\text { Health } \\
\text { Centers }\end{array}$ & $\begin{array}{c}\text { Both } \\
\text { Settings }\end{array}$ & $\begin{array}{r}\text { Hospital to Health Centers } \\
\text { difference, Mean (95\% CI) }\end{array}$ \\
\hline Diabetes Mellitus & $40.1 \%$ & $25.2 \%$ & $35.0 \%$ & $14.9 \%(11.8 \%, 18.0 \%)$ \\
Hypertension & $40.0 \%$ & $20.4 \%$ & $38.6 \%$ & $19.7 \%(10.1 \%, 29.3 \%)$ \\
Epilepsy & $63.4 \%$ & $58.6 \%$ & $60.2 \%$ & $4.8 \%(1.5 \%, 8.1 \%)$ \\
\hline
\end{tabular}

*Percentage of criteria met was calculated for every patient by dividing the number of criteria met for a patient by the total number of criteria for which the patient was eligible. Average percentage was calculated as an arithmetic mean of this proportion for patients in each group (Diabetes Mellitus, Hypertension and Epilepsy).

One way ANOVA was run to see if there was any variation in the quality of care for patients with the three disease conditions and significant variation has been observed in the quality of care provided to patients with different disease conditions (Sum of Squares between groups: 9.5, df: $2, \mathrm{P}<0.001$ ). Post hoc Bonferroni test was run for multiple comparison and it indicated that patients with epilepsy received better quality of care compared to those with Diabetes and Hypertension. But statistically significant difference was not observed between the quality of care provided to patients with Diabetes and those with Hypertension. Similar differences were observed both in health center and hospital setups. 


\section{Patient Follow-up}

Based on patient appointment systems in JUSH and study health centers, we considered a minimum of four follow-up clinic visits per year as a standard for follow-up of CNCDs. One hundred forty six $(83.9 \%)$ of diabetic patients, 106 (79.1\%) of hypertensive patients and $286(78.4 \%)$ of epileptic patients were found to have at least four follow-up clinic visits during the one year period prior to the data collection time. By the time of data collection, $44(25.3 \%)$ of diabetic patients, $21(15.6 \%)$ of hypertension patients and $80(21.9 \%)$ of epileptic patients were lost to follow-up (Table 4).

Table 4: Performance of health facilities on selected patient follow-up indicators, Health Facilities in Jimma Zone, 2010.

\begin{tabular}{|c|c|c|c|c|}
\hline & Selected patient follow-up indicators & $\begin{array}{r}\text { Hospital } \\
\text { (JUSH) }\end{array}$ & $\begin{array}{r}\text { Health } \\
\text { Centers }\end{array}$ & $\begin{array}{r}\text { Both } \\
\text { Settings }\end{array}$ \\
\hline \multirow{8}{*}{ 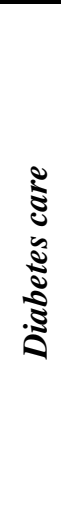 } & Had at least four follow-up clinic visits during the last one year period & $79.8 \%$ & $91.7 \%$ & $83.9 \%$ \\
\hline & Had at least one glycated hemoglobin test during the last one year period & $0.0 \%$ & $0.0 \%$ & $0.0 \%$ \\
\hline & Had regular FBS during scheduled visits* & $88.6 \%$ & $13.3 \%$ & $62.6 \%$ \\
\hline & $\begin{array}{l}\text { Had at least one time urinalysis for microalbuminuria during the last one } \\
\text { year period }\end{array}$ & $5.3 \%$ & $6.7 \%$ & $5.7 \%$ \\
\hline & $\begin{array}{l}\text { Had at least one dilated eye examination or referral to ophthalmology } \\
\text { clinic during the last one year period }\end{array}$ & $0.9 \%$ & $10.0 \%$ & $4.0 \%$ \\
\hline & Had at least one time feet examination during the last one year period & $5.3 \%$ & $15.0 \%$ & $8.6 \%$ \\
\hline & Had blood pressure measured at least once during the last one year period & $97.4 \%$ & $73.3 \%$ & $89.1 \%$ \\
\hline & Lost to follow-up $^{* *}$ & $22.8 \%$ & $30.0 \%$ & $25.3 \%$ \\
\hline \multirow{9}{*}{ 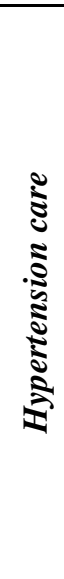 } & Had at least four follow-up clinic visits during the last one year period & $79.0 \%$ & $80.0 \%$ & $79.1 \%$ \\
\hline & Had regular blood pressure measurement* & $100.0 \%$ & $100.0 \%$ & $100.0 \%$ \\
\hline & $\begin{array}{l}\text { Had at least one time urinalysis for microalbuminuria during the last one } \\
\text { year period }\end{array}$ & $47.6 \%$ & $0.0 \%$ & $44.0 \%$ \\
\hline & Had at least one time serum creatinine test during the last one year period & $39.5 \%$ & $0.0 \%$ & $36.6 \%$ \\
\hline & Had at least one time LDL cholesterol test during the last one year period & $3.2 \%$ & $0.0 \%$ & $3.0 \%$ \\
\hline & $\begin{array}{l}\text { Had at least one time serum triglyceride test during the last one year } \\
\text { period }\end{array}$ & $3.2 \%$ & $0.0 \%$ & $3.0 \%$ \\
\hline & Had at least one time serum potassium test during the last one year period & $1.6 \%$ & $0.0 \%$ & $1.5 \%$ \\
\hline & $\begin{array}{l}\text { Had at least one time dilated eye examination or referral to ophthalmology } \\
\text { clinic during the last one year period }\end{array}$ & $1.6 \%$ & $0.0 \%$ & $1.5 \%$ \\
\hline & Lost to follow-up $^{* *}$ & $12.8 \%$ & $50.0 \%$ & $15.6 \%$ \\
\hline \multirow{7}{*}{ 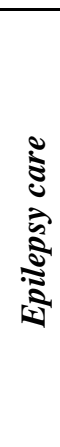 } & Had at least four follow-up clinic visits during the last one year period & $81.5 \%$ & $76.8 \%$ & $78.4 \%$ \\
\hline & Seizure type classification prior to AED initiation & $56.5 \%$ & $62.7 \%$ & $60.5 \%$ \\
\hline & Ever had classification of seizure type & $77.4 \%$ & $77.6 \%$ & $77.5 \%$ \\
\hline & Regularly asked for frequency of seizure attacks* & $100.0 \%$ & $100.0 \%$ & $100.0 \%$ \\
\hline & Blood Pressure measured at least once during the last one year period & $1.6 \%$ & $0.4 \%$ & $0.8 \%$ \\
\hline & EEG done at least once during the last one year period & $0.0 \%$ & $0.0 \%$ & $0.0 \%$ \\
\hline & Lost to follow-up $^{\text {*** }}$ & $5.6 \%$ & $30.3 \%$ & $21.9 \%$ \\
\hline
\end{tabular}


Diabetes care: During their follow-up visits in the one year period prior to data collection, none of the diabetic patients included in this study received glycated hemoglobin test. And FBS was not done as a follow-up test on a regular basis; only 109(62.6\%) of patients were having FBS regularly during their scheduled visits (on every visit for the six months prior to data collection). This was $88.6 \%$ for patients in JUSH and $13.3 \%$ for patients in the health centers. During the last one year, at least one time urinalysis for microalbuminuria, dilated eye examination and feet examination were provided only to $10(5.7 \%)$, $7(4.0 \%)$ and $15(8.6 \%)$ of patients, respectively. Nineteen $(10.9 \%)$ of the patients didn't get their BP measured even once during the one year period prior to data collection (Table 4)

Hypertension care: In JUSH, all follow-up laboratory tests were done only for less than half of the study subjects. Urinalysis for microalbuminuria and serum creatinine tests were done only for $59(47.2 \%)$ and $49(39.2 \%)$ of patients, respectively. And only 4(3.2\%), 4(3.2\%) and $2(1.6 \%)$ of patients had Low Density Lipid (LDL) cholesterol, serum triglyceride and serum potassium tests at least once over the one year period. And none of these laboratory tests were performed to patients attending care in health centers. Similarly, dilated eye examination to screen patients for eye complications or referral to ophthalmology clinic was done at least once only for $4(3.2 \%)$ of patients in JUSH and for none of those who were attending care in the health centers (Table 4).

Epilepsy care: Epileptic patients included in the study were found to have documented history of seizure for a median duration of 8 months, IQR (1, 36) prior to enrolment to epilepsy clinics. Out of the 365 patients, 144 (39.5\%) of them were started on Antiepileptic Drugs (AED) without classification of their seizure type. According to most recent available seizure classification, 278 $(76.1 \%)$ of them had generalized tonic-clonic seizure; $5(1.4 \%)$ had other forms of seizure and the rest $82(22.5 \%)$ of them never get classified throughout their period of follow-up. (Table 4)

Regarding treatment with AEDs, single drug regimen was initiated with either Phenobarbitone or Phenytoin for $326(89.3 \%)$ and $34(9.3 \%)$ of patients, respectively. On the other hand, $5(1.4 \%)$ patients were started with two AEDs. The mean daily dose of AED during initiation of treatment was $70.0 \mathrm{mg}$ (SE, 2.3) for Phenobarbitone and $80.9 \mathrm{mg}$ (SE, 7.9) for Phenytoin. Treatment was started at a daily dose of $100 \mathrm{mg}$ or more for $116(35.6 \%)$ of patients on Phenobarbitone and $14(41.2 \%)$ of patients on Phenytoin. Three patients were started on AED with the diagnosis of Febrile Seizure of which 2 are still getting AED refilled with no change in diagnosis.

All epileptic patients included in the study were found to be asked for frequency of seizure attacks on a regular basis when they made followup clinic visits. However, only $3(0.8 \%)$ of the patients got their BP measured and none of the patients got EEG or referred for EEG during the one year period prior to data collection (Table 4).

\section{Levels of disease control}

Among patients for whom outcome data was available, achievement of desired disease control outcomes was found very low where optimal level of disease control was achieved only for 47 (30.5\%), $40(38.5 \%)$ and $193(52.9 \%)$ of patients with Diabetes, Hypertension and Epilepsy, respectively (Table 5).

Among patients with at least one documented FBS result, controlled blood sugar level (less than $126 \mathrm{mg} / \mathrm{dL})$ was achieved in $39(36.1 \%)$ of patients at JUSH and $8(17.4 \%)$ of patients in the health centers. Patients attending care in JUSH were more likely to have controlled blood glucose level as compared to those in the health centers, OR 2.7, $95 \%$ CI $(1.1,6.3)$. 
Table 5: Levels of disease control among patients with CNCDs among patients with documented outcome data, Health Facilities in Jimma Zone, 2010.

\begin{tabular}{|c|c|c|c|c|c|c|c|c|c|c|}
\hline \multirow[b]{2}{*}{ Disease } & \multirow[b]{2}{*}{ Outcome } & \multicolumn{3}{|c|}{ Hospital (JUSH) } & \multicolumn{3}{|c|}{ Health Centers } & \multicolumn{3}{|c|}{ Both Settings } \\
\hline & & $\mathbf{n}$ & $\%$ & $\begin{array}{r}\text { Valid } \\
\%\end{array}$ & $\mathbf{n}$ & $\%$ & $\begin{array}{r}\text { Valid } \\
\%\end{array}$ & $\mathbf{n}$ & $\%$ & Valid\% \\
\hline \multirow{4}{*}{ 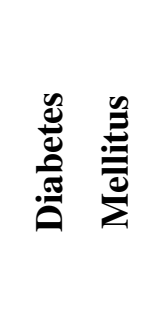 } & Controlled & 39 & 34.2 & 36.1 & 8 & 13.3 & 17.4 & 47 & 27.0 & 30.5 \\
\hline & Uncontrolled & 69 & 60.5 & 63.9 & 38 & 63.3 & 82.6 & 107 & 61.5 & 69.5 \\
\hline & No data & 6 & 5.3 & & 14 & 23.4 & & 20 & 11.5 & \\
\hline & Total & 114 & 100.0 & 100.0 & 60 & 100.0 & 100.0 & 174 & 100.0 & 100.0 \\
\hline \multirow{4}{*}{ 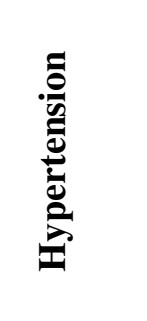 } & Controlled & 37 & 29.6 & 38.1 & 3 & 30.0 & 42.9 & 40 & 29.6 & 38.5 \\
\hline & Uncontrolled & 60 & 48.0 & 61.9 & 4 & 40.0 & 57.1 & 64 & 47.4 & 61.5 \\
\hline & No data & 28 & 22.4 & & 3 & 30.0 & & 31 & 23.0 & \\
\hline & Total & 125 & 100.0 & 100.0 & 10 & 100.0 & 100.0 & 135 & 100.0 & 100.0 \\
\hline \multirow{5}{*}{$\frac{\overrightarrow{0}}{\frac{0}{0}}$} & $\begin{array}{l}\text { Reported Seizure } \\
\text { during last six months }\end{array}$ & 68 & 54.8 & 54.8 & 63 & 26.1 & 26.1 & 131 & 35.9 & 35.9 \\
\hline & $\begin{array}{l}\text { Seizure free for } 6.0 \text { to } \\
11.9 \text { months }\end{array}$ & 10 & 8.1 & 8.1 & 31 & 12.9 & 12.9 & 41 & 11.2 & 11.2 \\
\hline & $\begin{array}{l}\text { Seizure free for } 12.0 \\
\text { to } 23.9 \text { months }\end{array}$ & 20 & 16.1 & 16.1 & 38 & 15.8 & 15.8 & 58 & 15.9 & 15.9 \\
\hline & $\begin{array}{l}\text { Seizure free for } \geq \\
24.0 \text { months }\end{array}$ & 26 & 21.0 & 21.0 & 109 & 45.2 & 45.2 & 135 & 37.0 & 37.0 \\
\hline & Total & 124 & 100.0 & 100.0 & 241 & 100.0 & 100.0 & 365 & 100.0 & 100.0 \\
\hline
\end{tabular}

Among patients with hypertension, 104 (77.0\%) were found to have at least three BP measures documented prior to the data collection time. Thirty seven $(38.1 \%)$ of patients from JUSH with at least three BP measures had controlled BP compared to $3(42.9 \%)$ among those from the study health centers. There was no significant difference between the two setups in the proportion of patients with controlled BP, OR 0.8
95\%CI $(0.2,3.9)^{1}$. The mean of average Systolic BP among these patients was $139.8 \mathrm{mmHg}, 95 \% \mathrm{CI}$ $(136.2 \mathrm{mmHg}, 143.3 \mathrm{mmHg})$ and that of average Diastolic BP was $89.2 \mathrm{mmHg}$, 95\%CI $(87.3 \mathrm{mmHg}$, $91.2 \mathrm{mmHg})$. One hundred twenty five $(92.6 \%)$ of the study subjects with hypertension had at least one time record of high BP (Systolic BP $\geq 140$ or Diastolic $\mathrm{BP} \geq 90$ ) during the one year period prior to data collection..

\footnotetext{
${ }^{1}$ Two cells (50\%) had expected count of less than 5.
} 
For epileptic patients, seizure free periods were measured as outcome indicators of provided medical care. Among the 365 study participants with the diagnosis of epilepsy, $234(64.1 \%)$ had a minimum of six seizure free months; $193(52.9 \%)$ had a minimum of twelve seizure free months and $135(37.0 \%)$ were found to have twenty four seizure free months prior to the data collection period. The median seizure free period among epileptic patients was 13.4 months, Inter Quartile Range (3.5 months, 41.1 months). Patients at health centers were more likely to be seizure free as compared to those at hospitals, OR of 3.4, $95 \%$ CI $(2.2,5.4)$ for six months seizure free period, $2.7,95 \% \mathrm{CI}(1.7,4.2)$ for twelve months seizure free period and $3.1,95 \% \mathrm{CI}(1.9,5.1)$ for twenty four months seizure free period.

\section{Resources for diagnosis and management of CNCDs}

Medical consultation to patients with CNCDs was found to be routinely provided primarily by resident physicians in JUSH while health officers and nurses provide services in the health centers. In all the health facilities involved in the study, we found separate rooms dedicated for outpatient consultation for patients with CNCDs. However treatment guidelines for CNCDs were lacking in all set-ups. Frequent stock out of routinely prescribed drugs and shortage of important laboratory tests were commonly faced problems in all of the health institutions. None of the study health facilities were found to have glycated hemoglobin test.

\section{DISCUSSION}

This study provided practically useful information regarding the quality of care provided to patients with CNCDs, particularly Diabetes, Hypertension and Epilepsy, which are reasons for majority of chronic illness clinic visits in Ethiopia. The findings indicated that quality of medical care, as measured by level of adherence to recommended processes of care and levels of disease control, is very low in both health care set-ups for the three conditions.

As defined by the Institute of Medicine of the National Academies (25), adherence to current professional knowledge in the provision of medical care is a major constituent of medical care quality determining the likelihood of achieving positive health outcomes. In this study, the level of adherence to recommended processes of care was only $35.1 \%, 38.5 \%$ and $60.1 \%$ for patients with Diabetes, Hypertension and Epilepsy, respectively, indicating apparent deviations from current scientific recommendations. Our findings showed lower degree of adherence to quality of care indicators as compared to findings from both developed countries (26-28) and developing ones $(29,30)$.

Similarly, the proportion of patients with controlled disease conditions was unacceptably very low in our study health facilities, lower than findings in other developing countries and consistent with studies conducted in other referral hospitals of Ethiopia (19;31-33). Such very low level of disease control could primarily be the result of the observed low physical and laboratory follow-up examinations, which negatively affect timely adjustment of dose and regimens.

Quality of care provided to patients with CNCDs was found relatively better in JUSH than in the health centers. Both adherence to recommended processes of care and achievement of desired health outcomes were better for diabetic and hypertensive patients attending care in JUSH as compared to those in health centers. However, a similar difference in outcomes was not observed for patients with epilepsy; epileptic patients attending care in health centers were found more likely to be seizure free for six, twelve and twenty four months as compared to those in the hospital. This might be due to more visible indicators of uncontrolled disease condition for epilepsy encouraging referral of uncontrolled cases to JUSH while keeping controlled cases to be managed in health centers.

Structured quality management programs and development of clinical practice guidelines showed effectiveness in improving and reducing variations in the quality of care provided to patients with wide range of clinical conditions including CNCDs (34-36). In this regard, this study showed that there was no clinical practice guideline for the management of patients with 
CNCDs in the study health facilities. This could be one of the possible explanations for the observed very low level of adherence to recommended processes of care in both health care setups. The low level of quality reported by studies from other Ethiopian health facilities could also be related to this shared problem of absence of clinical practice guidelines.

Though not sufficient, the presence of resources is a necessary condition for the provision of quality medical care to patients. In this study it was found that important laboratory tests and drugs were frequently lacking in the study health facilities. This could be the other potential reason for the observed non-adherence of clinical practice with current scientific recommendations.

While this study provided comprehensive information on structural, process and outcome measures of medical care quality for patients with CNCDs in different setups, the study has some limitations. The use of patient records as a source of data might have resulted in either underestimation or overestimation of some indicators calling for careful utilization of the findings. Another limitation of the study is related to the analytic technique we used to aggregate multiple process indicators where both overall percentage and patient average techniques assigned equal weights for all process indicators irrespective of their importance for achievement of desired outcomes. And the lack of complete outcome data has also limited us from analyzing the relationship between process and outcome measures of quality at patient level.

In conclusion, the quality of medical care provided to patients with CNCDs in Jimma Zone is very low both at the hospital and health center setups. Yet, patients attending medical care in JUSH received relatively better quality care as compared to those in health centers. Though some of the observed deviations from current scientific recommendations can be related to lack of laboratory equipments and reagents in both setups, poor adherence has also been observed in areas of care where adequate resources were available indicating the need for systematic quality improvement programs besides availing resources.
A chronic care model considering the capacity of different level health facilities should be developed to establish role differentiation for different level health facilities rather than variation in quality of care. In addition, minimum resource and service packages should be developed and be availed for both hospital and health center setups.

Expansion of chronic care to improve its accessibility, while at the same time reducing patient load on hospitals, should be supported with development of clinical practice guidelines and regular training of health workers to minimize variation in quality of care.

Comprehensive assessment of medical care quality covering more disease conditions will allow identification of priority areas for quality improvement in different level health care facilities.

\section{ACKNOWLEDGEMENTS}

This study has been supported by the Young Researchers Grant from the World Health Organization to Jimma University for which the researchers are grateful. We are also indebted to Dr Belete Habte (Head, Department of Internal Medicine, College of Public Health and Medical Sciences, Jimma University) who has reviewed the indicators selected for this study.

\section{REFERENCES}

1. World Health Organization. Preventing chronic disease: a vital investment: WHO global report. 2005.

2. Mayosi BM, Flisher AJ, Lalloo UG, Sitas F, Tollman SM, Bradshaw D. The burden of non-communicable diseases in South Africa. Lancet 2009;374(9693):934-47.

3. Juliet Addo, Liam Smeeth, David A.Leon. Hypertension in Sub-Saharan Africa: A Systematic Review. Hypertension 2007;2007(50):1012-8.

4. Unwin N., Mugusi F., Aspray T., et al. Tackling the emerging pandemic of noncommunicable diseases in sub-Saharan Africa: the essential NCD health intervention project. Public Health 1999;(113):141-6. 
5. Kearney PM, Whelton M, Reynolds K, Whelton PK, HJ. Worldwide prevalence of hypertension: a systematic review. Journal of Hypertension 2004;22(1):11-9.

6. Giles WH, Pacqué M, Greene BM, Taylor HR, Muñoz B, Cutler M, et al. Prevalence of hypertension in rural west Africa. The American Journal of the Medical Sciences 1994;308(5):271-5.

7. Agyemang $\mathrm{C}$, Bruijnzeels MA, OwusuDabo E. Factors associated with hypertension awareness, treatment, and control in Ghana, West Africa. Journal of Human Hypertension 2006;20(1):67-71.

8. Kendall-Taylor NH, Kathomi C, Rimba K, Newton CR. Comparing characteristics of epilepsy treatment providers on the Kenyan coast: implications for treatment-seeking and intervention. Rural Remote Health 2009;9(4):1253.

9. Epilepsy Canada. Epilepsy Facts. http://www epilepsy ca/eng/content/sheet html 2010Available from: URL: http://www.epilepsy.ca/eng/content/sheet.ht ml Accessed on 15 February 2010.

10. Tesfaye F, Byass P, Wall S. Population based prevalence of high blood pressure among adults in Addis Ababa: uncovering a silent epidemic. BMC Cardiovasc Disord 2009;9:39.

11. Mamo Y, Alemu S, Seid E, Tiley C, Prevett $\mathrm{M}$. The problem of epilepsy and its care in rural Ethiopia. Ethiop Med J 2008;46(3):267-72.

12. Oli K, Porteous J. Rheumatic heart disease among school children in Addis Ababa City: awareness and adequacy of its prophylaxis. Ethiop Med J 1999;37(3):155-61.

13. Oli K, Tekle-Haimanot R, Forsgren L, Ekstedt J. Rheumatic heart disease prevalence among schoolchildren of an Ethiopian rural town. Cardiology 1992;80(2):152-5.

14. Tekle-Haimanot R, Forsgren L., Stedt J. Incidence of epilepsy in rural central Ethiopia. Epilepsia 1997;(38):541-6.

15. Alemu S, Dessie A, Seid E, Bard E, Lee PT, Trimble ER, et al. Insulin-requiring diabetes in rural Ethiopia: should we reopen the case for malnutrition-related diabetes? Diabetologia 2009;52(9):1842-5.
16. Tilahun Yemane, Tefera Belachew, Bekalu Asaminew, Olana Befekadu. Type II Diabetes Mellitus in Jimma Town, Southwest Ethiopia. Ethiop J Health Sci 2007; 17(2)

17. The Transitional Government of Ethiopia. Health Policy of The Transitional Government of Ethiopia. 2003.

18. Oli K., Asmera J. Rheumatic heart disease in Ethiopia: could it be more malignant? Ethiop Med J 2004;(42):1-8.

19. Gill G, Gebrekidan A, English P, Wile D, Tesfaye S. Diabetic complications and glycaemic control in remote North Africa. QJM 2008;101(10):793-8.

20. Watkins P, Alemu S. Delivery of diabetes care in rural Ethiopia: an experience from Gondar. Ethiop Med J 2003;41(1):9-17.

21. Kadia Petricca, Yoseph Mamo, Abraham Haileamlak, Etalem Seid, Eldryd Parry. Barriers to Effective Follow-up Treatment for Rheumatic Heart Disease in Jimma, Ethiopia: A Grounded Theory Analysis of the Patient Experience. Ethiopian Journal of Health Sciences 2009;19(1):39-44.

22. Mamo Y, Seid E, Adams S, Gardiner A, Parry E. A primary healthcare approach to the management of chronic disease in Ethiopia: an example for other countries. Clin Med 2007;7(3):228-31.

23. Shibeshi W. Integrating chronic illness care in primary care settings in Ethiopia. 2005.

24. Reeves D, Campbell SM, Adams J, Shekelle PG, Kontopantelis E, Roland MO. Combining multiple indicators of clinical quality: an evaluation of different analytic approaches. Med Care 2007;45(6):489-96.

25. Institute of Medicine of the National Accademies. Medicare: A Strategy for Quality Assurance, Volume I. 1990. Washington, DC, The National Academy Press.

26. Asch SM, McGlynn EA, Hiatt L, Adams J, Hicks J, DeCristofaro A, et al. Quality of care for hypertension in the United States. BMC Cardiovasc Disord 2005;5(1):1.

27. McGlynn EA, Asch SM, Adams J, Keesey J, Hicks J, DeCristofaro A, et al. The quality of health care delivered to adults in the United States. N Engl J Med 2003;348(26):2635-45. 
28. Goldberg RW, Kreyenbuhl JA, Medoff DR, Dickerson FB, Wohlheiter K, Fang LJ, et al. Quality of diabetes care among adults with serious mental illness. Psychiatr Serv 2007;58(4):536-43.

29. bou El-Enein NY, Abolfotouh MA. An audit of diabetes care at 3 centres in Alexandria. East Mediterr Health J 2008;14(3):636-46.

30. Alberti H, Boudriga N, Nabli M. "Damm sokkor": factors associated with the quality of care of patients with diabetes: a study in primary care in Tunisia. Diabetes Care 2007;30(8):2013-8.

31. Seyoum B, Abdulkadir J, Berhanu P, Feleke Y, Mengistu Z, Worku Y, et al. Analysis of serum lipids and lipoproteins in Ethiopian diabetic patients. Ethiop Med J 2003;41(1):1-8.

32. Rahlenbeck SI, Gebre-Yohannes A. Prevalence and epidemiology of micro- and macroalbuminuria in Ethiopian diabetic patients. J Diabetes Complications 1997;11(6):343-9.
33. Harzallah F, Kanoun F, Elhouch F, Slimane H. [Quality of ambulatory care of noninsulin dependent diabetic patients]. East Mediterr Health J 2006;12(1-2):98-104.

34. Schafer I, Kuver C, Gedrose B, Hoffmann F, Russ-Thiel B, Brose HP, et al. The disease management program for type 2 diabetes in Germany enhances process quality of diabetes care - a follow-up survey of patient's experiences. BMC Health Serv Res 2010;10:55.

35. Samoutis GA, Soteriades ES, Stoffers HE, Philalithis A, Delicha EM, Lionis C. A pilot quality improvement intervention in patients with diabetes and hypertension in primary care settings of Cyprus 1. Fam Pract 2010;27(3):263-70.

36. Davies B, Edwards N, Ploeg J, Virani T. Insights about the process and impact of implementing nursing guidelines on delivery of care in hospitals and community settings. BMC Health Serv Res 2008;8:29. 